\begin{tabular}{|c|c|c|c|c|c|} 
Mansoura University \\
Faculty of Engineering \\
Mansoura Engineering Journal
\end{tabular}

\title{
Life Cycle Assessment of PV Systems: Integrated Design Approach for Affordable Housing in Al-Burullus Graduates Villages

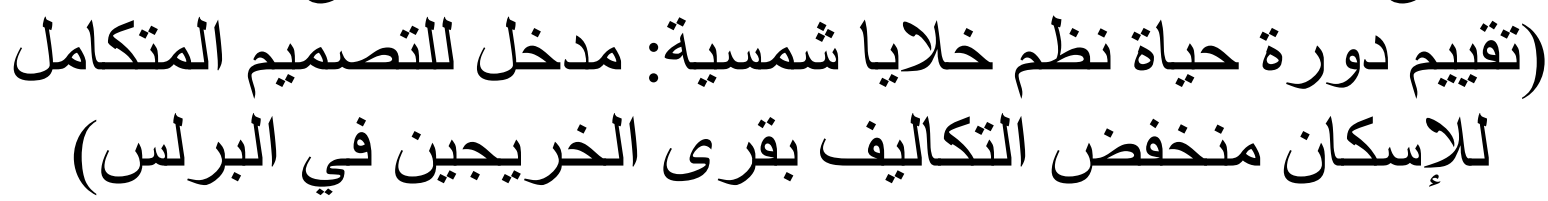

Mohamed M. ElDabosy and Sherif A. Sheta

KEYWORDS:
Life Cycle Assessment,
Building-integrated
Photovoltaics [BIPV],
Affordabler Housing
Design, Graduate
Villages, Hinterlands,
Al-Burullus.

Abstract - the integration of renewable energy techniques with building industry is a significant approach for the development of remote areas, which helps to create selfsustaining communities in terms of energy consumption; particularly in housing planning and design. To the North of AlBurullus Lake, three villages have been built by the Egyptian government in mid 90s to develop this vital region of the Egyptian north coasts. The optimal integration of affordable renewable energy techniques with these low income villages is the scope of a research project funded by Mansoura University as a part of the university vision to improve the quality of life and

Received: 20 February, 2018 - Accepted: 26 March, 2018

This study is carried out from a research project titled "combined renewable energy techniques for the development of Egyptian hinterlands" with Prof. Sherief Sheta as a PI and totally funded by Mansoura University research funding unit.

M. M. ElDabosy and S. A. Sheta are affiliated Architectural Engineering Department, Faculty of Engineering, Mansoura University, 35516 Egypt (email:mmdaposi@mans.edu.eg) develop remote areas. This paper tackles the environmental impacts of Building Integrated Photo-Voltaics [BIPV], and employs a case analysis comparison of possible systems in terms of Life Cycle Assessment [LCA]. To reach its goal, the study examines the scientific bases of life cycle assessment, PV life cycle analysis, basic LCA Indicators for PV Performance; all to be tested by an LCA software as a quantitative method to evaluate the proposed cases. The study concluded that Mono-crystalline PV has the minimum energy payback time [2.15 years for case 2]. While Mono-crystalline $\mathrm{PV}$ has the minimum $\mathrm{CO}_{2}$ emissions rate [58 $\mathrm{gCO}_{2} \mathrm{eq} / \mathrm{kWh}$ for case 1]. The study provides recommended guidelines for which type to be preferably used as an integrated affordable housing design system.

\section{INTRODUCTION}

$\mathrm{B}$ UILDING-Integrated Photovoltaic (BIPV) is now a part of every architect's vocabulary, as the installation of PV panels on roofs is the most practical method for distributing the investment cost and 
immediate the transition to solar technologies in dense cities and rural communities than is likely to occur at the utility scale. The international concept DESERTEC and VLS-PV has been issued to support the development of solar energy technologies in the light of the cooperation of EU, MENA, and Mediterranean countries (Kurokawa). The project aims at contributing the development of the following;

1) The population living in areas that are less than $3,000 \mathrm{~km}$ away from deserts,

2) Integration of renewable energy and transmission grids,

3) Socio-economic development,

4) Extensions to water supply and growing biomass in addition to long term objectives, and

5) Contribution of feasible conditions for the investments and regulatory framework in energy sector on countries located on the solar belt.

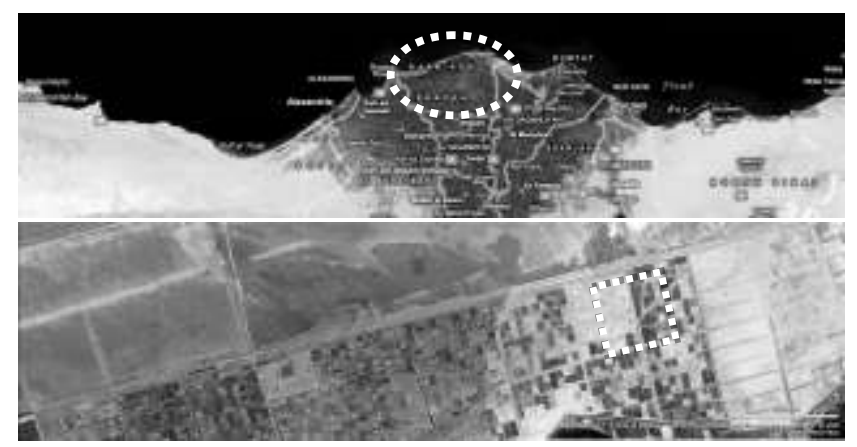

Fig.1. Selected study zone of Al-Burullus (research team from Google maps).

Hence, the strategic location of Al-Burullus Lake - located on the solar belt while being connected to the international coastal road and electricity link, see fig. 1- would provide an opportunity to study the feasibility of creating sustainable development which corresponds to the internatitual research perspectives, while contributing to better comminity access and improved feasibility of PV systems. Here, the study tackles the first VLS-PV stage "Establish small scale independent PV systems" by integrating stand-alone, several hundred watt-class PV systems with existing private dwellings, and installing 2:10 kW-class systems on the their roofs as the solar home system, the system should match the proper site and position (Partain).

The affordable social housing projects located in AlBurullus which called graduates villages represent a good start to study this prototype, as it consists of single story housing with typically design unit and directly connected to the electricity national grid. The potential of this project to play a pilot role in this field comes from the ability to multiply the experience in several locations along the international coastal road.

\section{RESEARCH BACKGROUND}

\section{A. Life Cycle Assessment Basis}

Life cycle assessment LCA is an approach to environmental management system implementation involving the quantitative evaluation of a product's overall environmental impact, aims at comparing and analyzing the environmental impacts of products and services [1]. Energy requirements and $\mathrm{CO}_{2}$ emissions throughout the whole life cycle of the product (including its manufacture, transport, use, disposal, etc.) are estimated in order to enable such evaluation, and the results can be used for related environmental assessment. The research and analysis scheme for LCA consists of the four stages goal and scope definition, inventory analysis, impact assessment and interpretation [2] as following points:

\section{1) Goal and scope definition}

To describe the underlying questions, the system boundaries and the definition of a functional unit for the comparison of different alternatives.

As using different boundaries obviously creates different results, defining and making boundaries known is important. Figure 2 shows typical boundaries for LCA of a PV system from the mining of its raw materials to its final disposal. The next consideration is the boundary for each stage. Boundaries involve products and services related to the item's life cycle. As the details vary in each case, it is important to fit the definition to the purpose of the product. For example, factors including the type of PV module, efficiency, array, foundation, installation method and operation method should be identified to build a suitable system. Indirect factors should also be considered as much as possible.

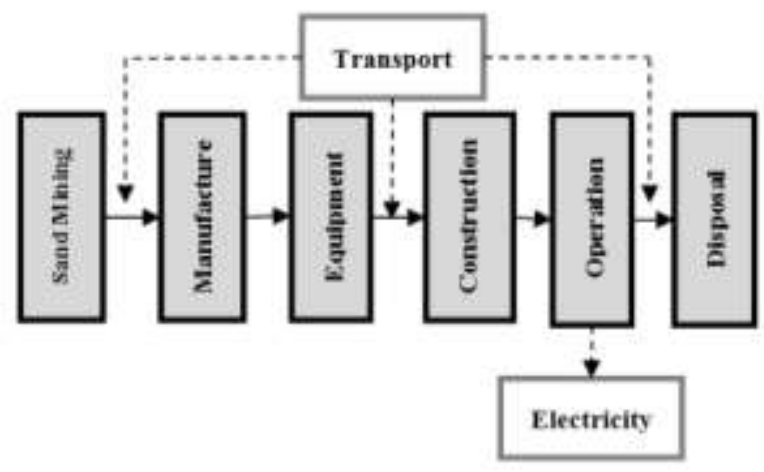

Fig. 2. Boundaries of LCA for a PV system [2]

\section{2) Inventory Analysis}

To investigate and record how is the flow of pollutants, materials and resources. The results of inventory analysis reflect the life cycle inventory data. It is performed to evaluate the amounts of environment-influenced materials consumed or produced during the object's life cycle. It involves pinpointing the processes involved in the life cycle and evaluating them quantitatively, then identifying all related environmentinfluencing materials. The object's data are subsequently evaluated as a whole [3].

\section{3) Impact Assessment}

The impact assessment role is to describe, characterize and aggregate well the intended elementary flows such as emissions and resource consumption. 
Impact assessment consists of three sequent steps as follow; the classification, characterization and weighting. Firstly, environment-influencing materials are categorized in terms of related influence events, then Impact potential is calculated based on inventory analysis.

\section{4) Interpretation}

The last part is to draw the final conclusions. The results of LCA may depend on research boundaries and approaches to inventory analysis. Accordingly, in related interpretation, the effects of operation methods should be discussed. Usually, the data used in LCA include estimates and referred information. For this reason, if the data affect the results significantly, sensitivity analysis should be included. The data availability is a major problem for establishing a high-quality inventory, because only a few producers provide reliable and verifiable data.

In Egypt, the absence of documented database for LCI is the main problem in research of this field. While, the terms of use of this database do not allow a full publication of the inventory data in such an article, nor would this be possible due to the extent of the information.

\section{B. PV Life Cycle Analysis}

The system boundaries include quartz reduction, silicon purification, wafer, panel and laminate production, manufacturing of converter and mounting infrastructure and 30 years of operation. Furthermore, transport of materials, of energy carriers, of semi-finished products and of the complete power plant, as well as waste treatment processes for production wastes and end of life wastes are considered in all process stages. The infrastructure for all production facilities with its land use has also been roughly assessed. Air- and waterborne process-specific pollutants are included as well. The photovoltaic system is divided into unit processes for each of the process stages. The basic assumptions for each of these unit processes are described in the following sections;

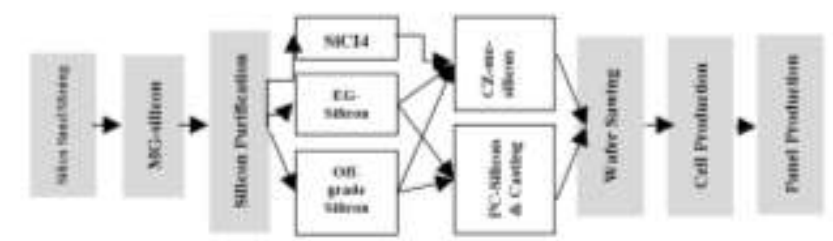

Fig. 3. Example of different sub-systems investigated for PV power plants [1]

1) Silicon Production

The production of metallurgical-grade silicon (MG-silicon) with a purity of about $99 \%$ is based on carbothermal reduction of silica sand, using petrol coke, charcoal and wood chips as reduction agents [1]. The consumption of reducing agents, electricity use, quartz input which represented by silica sand, and the emission of air- and waterborne pollutants carbon dioxide and sulfur dioxide and trace elements emitted with silicon dioxide dust are included in the LCA inventory.

\section{2) Silicon Purification}

In most cases the Silicon purification are in site process that provides three different products SiCI4, EG-silicon and off-grade silicon which are used in three different economic sectors; silicones (plastics) production, electronic industry and photovoltaic cells. The environmental impacts of the purification process have to be shared between these three coupled products [1]. In LCA; the problem of how to assign the environmental impacts between different couple products are termed the allocation problem. Different approaches to this problem are possible according to the ISO standards.

\section{3) Casting}

EG-silicon, off-grade silicon and solar-grade silicon SoGsilicon -future scenario for the production- are molten and cast into reusable molds. Wafers can be directly produced from these polycrystalline blocks. The inventory considers the energy use for melting and some material inputs, but no direct emissions to air and water, because information was not available. For Czochralski monocrystalline silicon (CZ-mcsilicon), The EG-silicon is molten and a growing crystal is slowly extracted from the melting pot.

\section{4) Wafer Sawing}

The silicon columns are sawn into wafers of $300 \mu \mathrm{m}$ thickness. Process data include electricity use, water and working material consumption such as stainless steel for saw blades, argon gas, hydrofluoric and hydrochloric acid. Production wastes to be treated and process-specific air- and waterborne pollutants are considered, based on information from the literature and environmental reports. Emissions of nitrogen nitrate and oxides due to surface etching with HNO3 might be important if these etching agents are used, but data for these emissions have been assessed because full information for Pc-Si wafer was not available.

\section{5) Solar Cell Production}

Production of solar cells with a size of $10 \times 10 \mathrm{~cm} 2$ includes purification and etching of the wafers. Afterwards wafers are endowed with phosphorus and, after further etching processes, front and rear contacts are printed. Process data include working material consumption (acids, oxygen, nitrogen and highly purified water), electricity consumption and production wastes. Furthermore, process and waterborne pollutants are considered, mainly hydrocarbons and acids. Cell efficiencies are estimated with data provided by several different producers for their actual products.

6) Panels and Laminate Production

The construction of solar panels had inserted in inventory process, as solar cells are embedded in layers, one each on the front and the back [4]. The production process data include materials and energy consumption as well as the treatment of production wastes. Physical calculation might by change from the studies predictions. Possible changes in the mounting infrastructure haven't been assessed separately for the future scenario.

7) Mounting Systems

Panels are mounted on top of houses and laminates are 
integrated into slanted roofs and facades. Flat roof systems are mounted on the roof. Process data for different systems include construction materials (e.g., aluminum, plastics, steel) and process energy. Transport of the photovoltaic system from the manufacturing site to the place of operation include personnel transport for mounting.

8) Converters and electric equipment

Process data for manufacturing the converter and of the electric equipment include construction materials, energy requirement (for converter only), packaging materials (for converter only) and transport services. Electronic components of the converter and electric equipment have not been considered in the inventory due to lack of data.

\section{9) Operation and Dismantling of PV power plants}

The average solar irradiation is measured in $\mathrm{kWh} / \mathrm{m} 2 /$ year. The calculations of photovoltaic plants in operation show an average electricity production for study period and due to the changing meteorological conditions the annual yields is varied from year to another. For the inventory of flat and slanted roof installations only the best plants with have been considered to disregard the less efficient facade installations. An average façade system with vertically oriented panels is calculated [4]. Also total amount of water that using for cleaning the panels once a year is included in the inventory.

\section{METHODOLOGY}

\section{A. Basic LCA Indicators for PV Performance}

In any LCA study, the purpose depends on the operator. However, when the operator evaluates a photovoltaic (PV) system, the main research point or characteristic relates to energy generation. This is a significant difference between PV systems and other products. When a building developer discusses new energy supply systems (e.g., in relation to buildings with low carbon emissions and high energy efficiency), LCA can highlight the potential of PV systems and useful materials. This is expected to provide two advantages, the first of which is PV system optimization. When a developer studies the installation of a PV system, the environment of the installation site must be considered. To ensure optimization, a variety of variables (e.g., cost and $\mathrm{CO}_{2}$ emissions) are discussed. If LCA is used, the system can be optimized from an environmental viewpoint. The second advantage is comparability. When comparing energy generation technologies (e.g., when researching the possible installation of a PV system as a supply of alternative energy as opposed to other generation systems, or when installing energy supply systems based on multiple generation technologies), the evaluation methods and rules applied must be uniform. In such cases, LCA can provide quantitative results, thereby enabling comparison of each technology on an equal footing.

1) Energy Payback Time (EPBT)

Energy payback time is defined as the period required for renewable energy system to generate the same amount of energy -either primary or $\mathrm{kWh}$ equivalent- that was used to produce the system itself. An important yardstick for the assessment of renewable energy systems is the estimation of the energy and/or environmental payback time. In some publications [5] [6], the energy payback time was defined as the time until the electricity production of the plant equals the energy use during the production of the plant. This does neither take into account differences in the type of energy (e.g., nuclear or fossil resources) nor differences for the quality (e.g., electricity or heat use). Here we describe the time until environmental impacts from the production of the plant have been leveled out due to avoiding resource use and/or emissions of a conventional reference system that produces the same amount of electricity. The outcome of such a comparison is influenced by the choice of the reference system on the one hand and the indicator on the other, which shall be demonstrated with some examples. Here we consider a modern natural gas-fired gas combined cycle power plant as the reference system. Environmental impacts are allocated based on the energy content of the two products, heat and electricity. It is assumed that the use of photovoltaic power plants can avoid the installation of such a facility. The total energy payback time could be

\section{Energy payback time EPBT \\ $=\frac{\left(\begin{array}{c}\text { E material }+ \text { E manufacture }+ \text { E transport } \\ + \text { E installation }+ \text { E operation }+ \text { E endoflife }\end{array}\right)}{\left(\begin{array}{c}\text { E annual energy generation }- \text { E annual energy demand } \\ \text { for operation and maintenance })\end{array}\right.}$

The environmental payback time for greenhouse gas emissions is similar to this for non-renewable energy resources. This picture changes if emissions are taken into account. Weighting the impact with the method of ecological scarcity UBP gives an environmental payback time of about 25 years, whereas the payback time evaluated with Ecoindicator is only slightly higher than for the energy demand. The picture would also change if other reference systems were considered. This can be assumed with the help of comparing different electricity systems. The studies have cleared that the energy demand for producing the photovoltaic plants is as high as the energy demand for the operation of the gas power plant during 3 to 6 years [1]. There is no direct energy use during operation of the PV plant. Thus, it is five to ten times shorter than the expected life time of the photovoltaic power plants. These examples showed that it is necessary to discuss the assumptions for a payback time in detail and that the results of such an analysis are quite dependent on these assumptions.

\section{2) Greenhouse Gas Emissions}

The greenhouse-gas GHG emissions during the life cycle stages of PV system are estimated as an equivalent of $\mathrm{CO}_{2}$ using an integrated time horizon of 100 years, the major emissions included as $\mathrm{GHG}$ emissions are $\mathrm{CO}_{2}, \mathrm{CH}_{4}, \mathrm{~N}_{2} \mathrm{O}$ and $\mathrm{CFC}$ [7]. The $\mathrm{CO}_{2}$ emission rate is a useful index for determining how effective a PV system is in terms of global warming. Generally, this index is used for comparison 
between generation technologies. As a PV system does not operate in the same way as a tree, there is no payback of $\mathrm{CO}_{2}$ emissions as such. However, some research on comparisons between PV systems and other fossil fuel generation technologies have used $\mathrm{CO}_{2}$ payback time as a metric. In these studies, PV systems were viewed as an alternative to fossil fuels and as offering a corresponding reduction in $\mathrm{CO}_{2}$ emissions, which allowed calculation of the $\mathrm{CO}_{2}$ payback time. However, this paper does not deal with the concept of $\mathrm{CO}_{2}$ payback time [2]. The $\mathrm{CO}_{2}$ emissions rate could be calculated for the following equation;

$$
=\frac{\text { Total } \mathrm{CO} 2 \text { emission during life cycle }[\mathrm{g} \mathrm{CO} 2]}{\text { Annual power generation }\left[\frac{\mathrm{kWh}}{\mathrm{year}}\right] * \text { Lifetime [year] }}
$$

Other renewable energy systems such as wind, hydro and wood power plants show lower environmental impacts than the photovoltaic power plants with all LCIA methodologies applied here. Power plants using natural gas or oil show much higher impacts. Greenhouse gas emissions for PV range from 39:110 $\mathrm{gCO}_{2} \mathrm{eq} / \mathrm{kWh}$. Hydropower has the lowest GHG emissions of $4 \mathrm{gCO} 2 \mathrm{eq} / \mathrm{kWh}$ while an oil power plant has the highest with $880 \mathrm{kgCO}_{2}$-eq $/ \mathrm{kWh}$. Nuclear power has lower greenhouse gas emissions and Eco-indicator $(\mathrm{H}, \mathrm{A})$ scores, but a higher nonrenewable energy use and higher eco-points [8]. Thus it can be concluded that PV is better than the conventional power plants based on non-renewable energy resources in many cases. On the other side environmental impacts of alternative renewable energy systems are lower. This is true even for the assumption of an improved PV production chain in the future. This analysis is valid for Switzerland, but not for other countries with other prerequisites (e.g., climatic conditions) for the different energy systems [9].

\section{B. LCA Software}

There are many software applications makes LCA calculations more accurate and certified based on the suitable database of life cycle inventory. Besides the scientific benefits of using LCA programs, these software help deliver more sustainable products \& reduce operational costs for your organization \& supply chain. By using these programs, all sectors could enhance sustainability decision-making and LCA projects, businesses can build sustainable brands, which consumers increasingly prefer. Businesses gain consumer trust through quantified and verifiable information to substantiate their sustainability labeling and communications.

Quantifying the life-cycle impact of a product will also enable a company to assess its supply chain to identify product categories with the highest impacts; the drivers behind the product's energy use performance, carbon footprint, waste and water footprint; and the hotspots where sustainability efforts can be concentrated. Community, government and several organizations can set goals and Key Performance Indicators (KPIs) with collective norms for product sustainability, building a more sustainable portfolio. The most common software used in LCA is following:

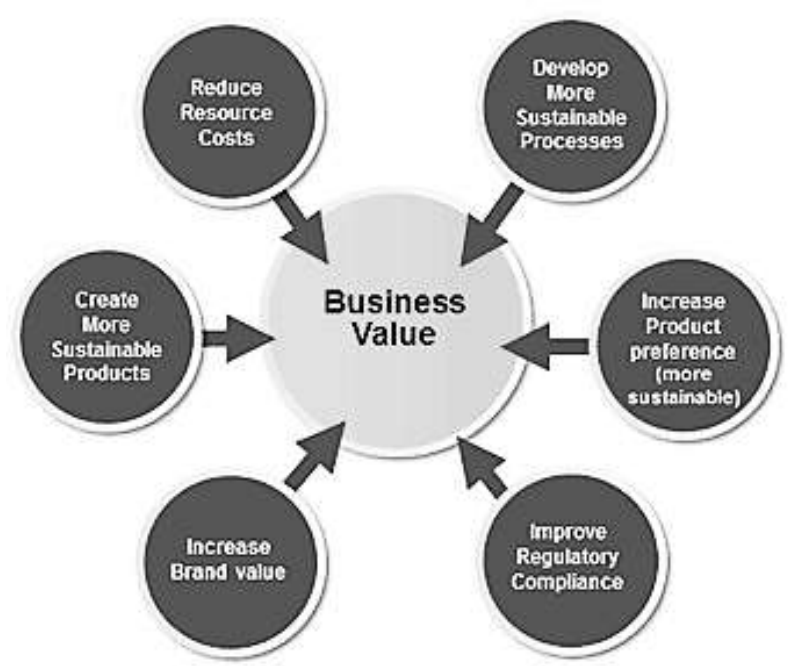

Fig. 4; Business value of using LCA software

\section{1) Open LCA}

The idea of the openLCA software emerged in 2006. It was quite simple, and basically three-fold [10]:

Design and build a fast, reliable, high-performance, modular framework for sustainability assessment \& life cycle modeling, that allows visually attractive and flexible modeling, for sophisticated and simple models, in a standard programming language, using only widely available Open Source software.

Create a contributing programming community.

Build modules for the framework, and enable users to build their own modules.

Idea was that freely available software for LCA and related approaches will open many different, new application fields in science, education, training, and peer-review. Moreover, publishing the source code will allow in-depth comparison of calculation procedures. It will demand high quality coding from us and, not the least, it will enable any user to implement any additional module as required or modify the source code where needed.

Since its beginning, and so far, the project is "run" and managed exclusively by Green Delta in Berlin, with a core openLCA development team working at Green Delta. There has always been a high public interest, and a broad external testing community. There has also been external support, from an initial "funding consortium" and from different research and industry projects. Recently, the project is expanding into a true network of partners, contributors, supporters, and a user community. The openLCA framework and the openLCA format converter are open source software, made publicly available under the Mozilla Public License.

2) $\mathrm{GaBi}$

A new generation produce sustainability solution with a powerful LCA engine to support the following business applications [11]:

LCA design for environment: developing products that 
meet environmental regulations, Eco-efficiency: reducing material, energy and resource use in the most cost-effective way, Eco-design: developing products with smaller environmental footprints such as fewer GHG emissions, reduced water consumption and waste, Efficient value chains: enhancing efficiency of value chains e.g. $R \& D$, design, production, suppliers, and distribution.

Life Cycle Costing; Cost reduction: designing and optimizing products and processes for cost reduction. Life Cycle Reporting; Sustainable Product Marketing: product sustainability labels \& claims, Environmental Product Declarations (EPDs). Sustainability Reporting: environmental communication \& product sustainability reporting.

LCA knowledge sharing: reporting and analysis for internal departments, management and supply chain. Life Cycle Working Environment: Responsible manufacturing: developing manufacturing process that address social responsibilities

Gabi software is developed by a private sector company in Germany under title of think step global, and has many branches worldwide [11]. It also provides an easily accessible and constantly refreshed content database that details the costs, energy and environmental impact of sourcing and refining every raw material or processed component of a manufactured item. In addition, it looks at the impact on the environment presenting alternative options for manufacturing, distribution, recyclability, pollution and sustainability.

\section{3) LCA Calculator}

This software generated and developed by LCA Calculator Ltd, a company located in London, UK. LCA Calculator is an easy and powerful software tool for evaluating the effects that a product or service has on the environment over its life cycle. The tool evaluates each phase chronologically from the extraction and processing of raw materials, to the manufacturing, packaging and marketing processes, to the use, re-use and maintenance of the product, and on to its eventual recycling or disposal as waste.

By measuring each of the steps you can understand and estimate the total impact of the product. In many cases it will be one specific area that tends to have the biggest impact and the LCA Calculator will point that area out so that a change in the design can be made.

By understanding all the impacts, one can take necessary measures to reduce the environmental impact and make processes more sustainable and environmentally friendly. As well as for in-depth analyses of existing products, the LCA Calculator can also be used to quickly assess 'what if?' scenarios and identify changes and improvements to new product lines.

\section{Research process}

The operations such as mining, industries, transportation, implementation (constructions), operation and demolishing are monitored and recorded for several periods in order to get an accurate database for any future studies. LCA database for Egyptian community and industries aren't available for many software. This study tries to overcoming this problem through mixed methods of using firstly the LCA Calculator software database and then apply manual calculation for the four case to reach the target results.

\section{Case Study}

The integration of renewable energies in the rural housing projects helps to reduce the use of agricultural residues, gasoline, and electricity to heat the water for the daily activities of peoples there, as it contributes environmentally, the mitigation of smokes and energy consumption. Achieving the following objective;

$\square$ Social awareness; abandonment of the traditional methods concerning the pollution, energy crisis and climatic changes.

$\square$ Quality of life; improving sanitation help, and therefore lead to health benefits for the poor residents.

$\square$ Socio-economic; generating employment opportunities for youth, and provide educational and training programs.

$\square$ Financial; attracting the involvement of private sector, and encouraging the policy-makers to support environmental activities and renewable energy.

Figure 5 and 6 show the physical reality of site before development and the project vision after PV integrated system. The feasibility study of project is a significant research work; LCA is a kind of feasibility studies that tries to compare the environmental impacts of different prototypes. Over the last thirty years, hundreds of life cycle assessments (LCAs) have been conducted and published for a variety of residential and utility-scale solar photovoltaic (PV) systems. These LCAs have yielded wide-ranging results.

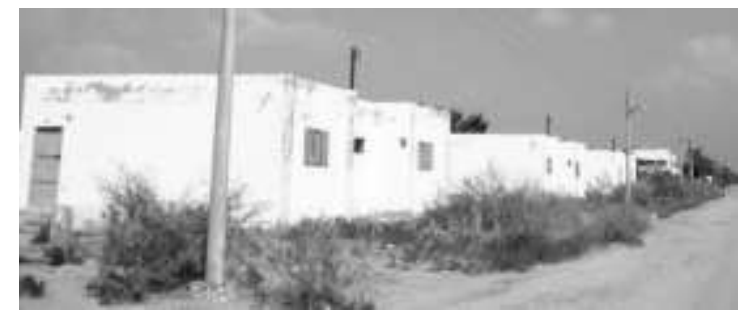

Fig. 5, physical reality of Al-Burullus housing units (research team)

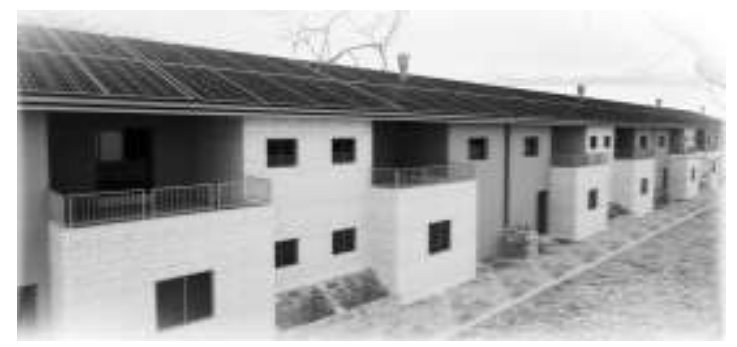

Fig. 6, Al-Burullus housing units' future vision (research team)

Variation could be attributed to differences in technologies evaluated (i.e., differing system designs, commercial versus conceptual systems, system operating assumptions, technology improvements over time) and LCA methods and assumptions. The National Renewable Energy Laboratory (NREL) recently led the Life Cycle Assessment (LCA) Harmonization Project, 
a study that helps to clarify inconsistent and conflicting life cycle GHG emission estimates in the published literature and provide more precise estimates of life cycle GHG emissions from PV systems. Analysts developed and applied a systematic approach to review LCA literature, identify primary sources of variability and, where possible, reduce variability in life cycle GHG emissions estimates through a process called "harmonization". Harmonization was performed by adjusting published GHG emission estimates to achieve consistent values for these key technical parameters;

$\square$ Solar irradiation, the average energy flux from the sun, in kilowatt-hours per square meter per year $\left(\mathrm{kWh} / \mathrm{m}^{2} /\right.$ year).

$\square$ Operating lifetime of the PV system and components (years). Life time is usually estimated 25-30 years.

$\square$ Module efficiency, the percentage of the solar energy converted to direct current electricity by the module.

$\square$ Performance ratio, the ratio of alternating current electricity actually produced by the system, after accounting for losses, to the electricity calculated based on the direct current-module efficiency and irradiation.

\section{A. Results}

Results for two cases in each mono and multi crystalline; case one for single house rooftop panels and case two for semi attached houses rooftop.

TABLE I

UNITS FOR MAGNETIC PROPERTIES

\begin{tabular}{|c|c|c|c|}
\hline \multicolumn{4}{|c|}{ Basic Data } \\
\hline $\begin{array}{l}\text { Case Study } \\
\text { Location }\end{array}$ & $\begin{array}{l}\text { Sedi Salem, } \\
\text { Al-Burullus } \\
(31.45,30.62)\end{array}$ & & \\
\hline $\begin{array}{l}\text { Solar Irradiation } \\
\left(\mathrm{kWh} / \mathrm{m}^{2} / \text { year }\right)^{\mathrm{a}}\end{array}$ & 1900:2200 & & \\
\hline System Lifetime & 25 years & & \\
\hline \multicolumn{4}{|c|}{ Crystalline Silicon Module Efficiency and Energy Requirements } \\
\hline \multirow{2}{*}{ Mono-crystalline } & $14.0 \%$ & 4 & $+*$ \\
\hline & $4,100 \mathrm{MJ} / \mathrm{m}^{2}$ & & \\
\hline \multirow{2}{*}{ Multi-crystalline } & $13.2 \%$ & & \\
\hline & $4,230 \mathrm{MJ} / \mathrm{m}^{2}$ & & \\
\hline \multicolumn{4}{|c|}{ Performance Ratio } \\
\hline $\begin{array}{l}\text { Ground- } \\
\text { Mounted }\end{array}$ & 0.80 & \multirow{2}{*}{\multicolumn{2}{|c|}{$\begin{array}{l}\text { The project selects the rooftop system } \\
\text { despite the low performance ratio } \\
\text { because of the existing courtyards. }\end{array}$}} \\
\hline Rooftop & 0.75 & & \\
\hline \multicolumn{4}{|c|}{ Cases Calculation Results } \\
\hline & & $\begin{array}{l}\text { EPBT } \\
\text { (year) }\end{array}$ & $\begin{array}{c}\mathrm{CO}_{2} \text { emissions rate } \\
\left(\mathrm{g} \mathrm{CO}_{2} \mathrm{eq} / \mathrm{kWh}\right)\end{array}$ \\
\hline \multirow{2}{*}{ Mono-crystalline } & Single house & 2.3 & 58 \\
\hline & Semi-attached & 2.15 & 96 \\
\hline \multirow{2}{*}{ Multi-crystalline } & Single house & 2.7 & 68 \\
\hline & Semi-attached & 2.65 & 110 \\
\hline
\end{tabular}

${ }^{a}$ International Network for Sustainable Energy,

http://www.inforse.org/europe/dieret/Solar/solar.html

This calculation show that the system works more efficient for area duplication as the $\mathrm{CO}_{2}$ equivalent not duplicated for area duplication, also the energy payback time is better in the second cases for mono- \& Multi-crystalline PV panels. That's mean the more PV constructed area the less environmental impact, the results matches with the calculation of similar sites
[4] [12], this proof the valuable studies in the Egyptian case.

\section{B. Discussion}

The life cycle GHG emissions of building integrated PV cells are compared with other electricity generation technologies. Results show that:

$\square$ Total life cycle GHG emissions from solar PV systems are similar to other renewables and nuclear energy, and much lower than coal.

$\square$ Integration increases the precision of life cycle GHG emission estimations.

$\square$ Integration has a small effect on the central estimate for each technology.

$\square$ Life cycle GHG emissions appear broadly similar.

Life cycle assessment of mono-crystalline, poly-crystalline and most advanced and consolidate technologies for the solar panel production has been studied [13] [14], of the harmonization parameters investigated, adjusting reported results to a consistent solar irradiation assumption had the greatest impact on reducing the variability in estimated GHG emissions from c-Si PV technologies. Solar irradiation directly influences the power generated from a PV system and varies by location and season, time of day, and weather. Adjustment to a consistent operating lifetime is also a driving factor in decreasing the variability of the harmonized data. Additional analysis comparing Mono-Si and multi-Si technologies -show in fig.6- suggest that these don't significantly differ in EPBT and life cycle $\mathrm{CO}_{2}$ emissions for different four cases
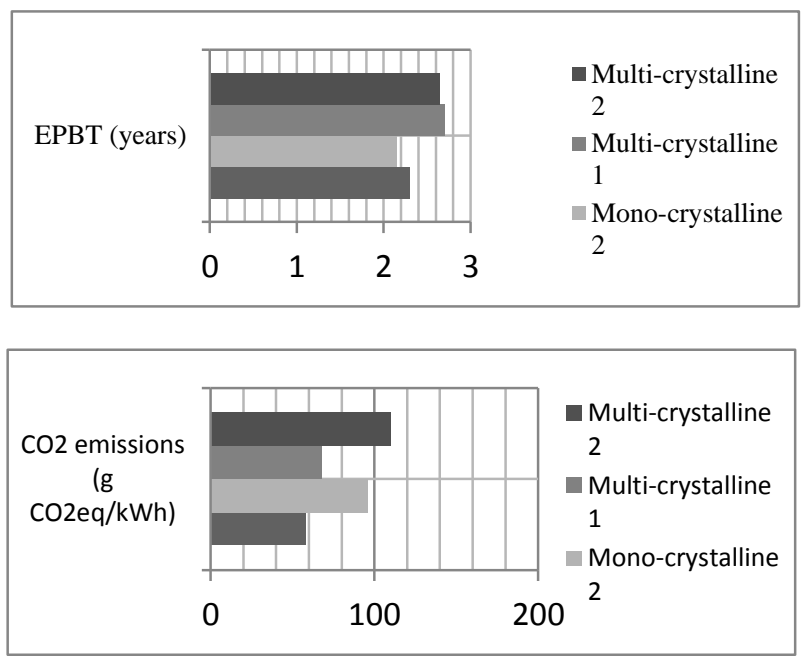

Fig. 6. Energy payback time and $\mathrm{CO}_{2}$ emissions for the four cases (Authors).

In addition, no significant differences in GHG emissions from ground mounted and roof-mounted systems were observed, so the research depends on roof systems in order to conserve the existing courtyards. The results of this research provide an initial estimate potentially useful for decision makers and investors. More types of PV such as the thin layer PVs in CdTe obtain better performances in term of EPBT and GHG emissions than silicon based one [15]. 


\section{CONCLUSION AND RECOMMENDATIONS}

The study presented several aspects of integrating PV to existing buildings, which has recently become a highly tackled source of energy for future Egypt. In conclusion of this research, the study recommends using the Mono-crystalline PV type as an affordable BIPV system for the low income housing units of the graduation villages at Al-Burullus. This type of photovoltaic cell would yield more favorable results in terms of energy payback and minimized $\mathrm{CO}_{2}$ emissions rate. Though still having relatively higher initial cost than other energy sources, Mono-crystalline PV type would have a good potential if locally fabricated. Future research is needed to study the local market behavior of each of these segments towards such applications.

The results of this paper confirm that the compacted urban design and attached housing buildings approach are the more appropriate type for this kind of integration with photovoltaic techniques. The larger space of connected PV systems leads to economic construction, operation, transportation and disposal which results on reduction of energy payback and $\mathrm{CO}_{2}$ emissions rate along the system life cycle.

Additional studies on PV systems are needed to understand the key sources of variability in life cycle $\mathrm{CO}_{2}$ estimates. LCAs should continue as module and utilization efficiencies improve and as PV manufacturing locations shift. Future assessments should also consider the systems-level effects of integrating variable generation sources onto the existing grid to better understand the impacts on GHG emissions from conventional generation sources.

\section{ACKNOWLEDGEMENT}

This paper carried out from a research project titled "combined renewable energy techniques for the development of Egyptian hinterlands" funded by Mansoura University research funding unit. The researchers thank all research team in the Egyptian Sustainable Urbanism laboratory and all stakeholders in Al-Burullus region for valuable data and continuous support to complete this study.

\section{REFERENCES}

[1] N. Jungbluth, Life Cycle Assessment of Crystalline Photovoltaics. Uster, Switzerland: John Wiley \& Sons, Ltd., 2005.

[2] M. Ito, "Life Cycle Assessment of PV Systems," in Crystalline Silicon; Properties and Uses, S. Basu Ed. Shanghai, China: InTech, 2011.

[3] V. Kim and H. Fthenakis. (2011). Photovoltaics: Life-Cycle Analysis. Solar Energy, (85), pp. 1609-1628.

[4] N. Jungbluth, M. Tuchschmid and M. Wild-Scholten, Life Cycle Assessment of Photovoltaics. Petten, Netherlands: ESU-services Ltd., 2008.

[5] T. Risto and K. Aija, Comparison of electricity generation costs: research report EN A-56. Lappeenranta, Finland: Lappeenranta University of Technology, 2008.

[6] "World energy resources". England: World Energy Council, 2016.

[7] "The IPCC Physical science basis, the $5^{\text {th }}$ assessment report". Stockholm: IPCC UN Publications, 2013.

[8] D. N. Sovacool and K. Benjamin (2014). Assessing the lifecycle greenhouse gas emissions from solar PV and wind energy. A critical meta-survey. Energy Policy, (65) pp. 229-244.

[9] M. Udaeta, C. Oliveira, F. Antonio and P. Kanayama (2013). Innovative Solar-House Aiming at Zero Annual Electricity Consumption with Energy Conservation and GHG Reduction. International Journal of Engineering and Innovative Technology (IJEIT), 3(3).

[10] A. Ciroth (2017). openLCA software, Green Delta GmbH, Berlin [Online]. Available; http://www.openlca.org/

[11] L. Guillon (2017). GaBi Software, thinkstep, Grmany [Online]. Available; http://www.gabi-software.com/international/databases/

[12] Y. Fu, X. Liu, and Z. Yuan (2015). Life-cycle assessment of multicrystalline photovoltaic (PV) systems in China. Journal of Cleaner Production (86). pp. 180-190.

[13] A.F. Sherwani and J.A. Usmani (2010). Life Cycle Assessment of Solar PV based Electricity Generation Sysems: A Review, Renewable and Sustainable Energy Reviews, 1(14), pp. 540-544.

[14] K. Bekkelund, "A Comparative Life Cycle Assessment of PV Solar Systems". Master of Energy and Environmental Engineering, department of Energy and Process Engineering, Norwegian University of Science and Technology, 2013.

[15] S. Gerbinet, S. Belboom and A. Léonard (2014). Life Cycle Analysis (LCA) of photovoltaic panels: A review. Renewable and Sustainable Energy Reviews, 38. pp. 747-753. 